\title{
¿CÓMO PENSAR HOY LA TENSIÓN ENTRE CONSTITUCIONALISMO Y DEMOCRACIA? UNA PERSPECTIVA DESDE EL CONSTITUCIONALISMO DEMOCRÁTICO*
}

\author{
HOW TO CONCEIVE THE CONFLICT BETWEEN CONSTITUTIONALISM AND \\ DEMOCRACY TODAY? A VIEW FROM THE DEMOCRATIC CONSTITUTIONALISM
}

\author{
Leonardo García Jaramillo**
}

\begin{abstract}
RESUMEN: desde el surgimiento de las concepciones normativas de la democracia, y a partir del cambio en el paradigma constitucional luego de la Segunda Guerra, surgió una tensión por la realización simultánea de dos fines: el autogobierno colectivo (la democracia) y la garantía de derechos y principios (la constitución). Dicha tensión se ha expresado, por ejemplo, cuando los tribunales constitucionales derogan una ley con amplio respaldo parlamentario, exigen que se tomen determinadas medidas de política pública o interpretan una disposición constitucional de forma tal que se decide a favor de un grupo en un tema moralmente complejo. Cómo fundamentar los límites constitucionales a la acción política, cómo articular adecuadamente el rol institucional de los tribunales con el respecto al principio mayoritario, cuál debe ser el rol de los tribunales constitucionales frente a la sociedad civil organizada y cómo aumentar la legitimidad democrática de la constitución. Estas cuestiones, entre otras, son abordadas por el constitucionalismo democrático y, así, aporta elementos para considerar nuevas formas de razonar acerca de las maneras cómo concebir dicha tensión.
\end{abstract}

PALABRAS CLAVE: Constitucionalismo. Constitucionalismo democrático. Constitucionalismo discursivo. Democracia. Legitimidad política.

ABSTRACT: Since the emergence of normative conceptions of democracy and from the change in the constitutional paradigm after WWII, a tension arose for the simultaneous achievement of two goals, namely, collective self-government (democracy) and the guarantee of fundamental rights and principles (constitution). This tension is expressed, for example, when the constitutional courts revoke a widely accepted law, require certain policy to be enforced, or interpret a constitutional provision in a way that favors a certain group on a morally complex topic. How to support constitutional limits to political action, how to properly articulate the institutional role of the courts with respect to the majority principle what should the role of constitutional courts be with respect to well-organized civil society, how to increase the constitution's democratic legitimacy. These issues,

\footnotetext{
Primera versión impartida como conferencia en el Seminario Internacional Novas Perspectivas para o Constitucionalismo e a Democracia. Universidade Federal do Paraná - Brasil, marzo de 2015. Presenta a su vez resultados de la investigación Activismo judicial y construcción de una dogmática de los márgenes de acción al legislativo, desarrollada actualmente como tesis en la Università Degli Studi di Genova - Italia. Agradezco muy especialmente a Vera Karam, Miguel Godoy, Katya Kozicki, Melina Fachin, Estefânia Maria Queiroz, Amélia Sampaio, Bruno Lorenzetto y José Arthur Castillo por sus observaciones y por su gentil hospitalidad en Curitiba. Agradezco a Thomas Bustamante el intercambio de ideas durante las sesiones que nos correspondieron compartir en el Seminario.

** Universidad EAFIT - Colombia, Departamento de Gobierno y Ciencias Políticas. Actualmente es estudiante de posgrado, Università Degli Studi Di Genova - Italia.E-mail: lgarciaj@eafit.edu.co
} 
among others, are addressed by democratic constitutionalism and thus provide elements to consider new ways of thinking about how to conceive this tension.

KEYWORDS: Constitutionalism. Democracy. Democratic constitutionalism. Discursive constitutionalism. Political legitimacy.

SUMARIO: Introducción. 1 Excurso. 2 Tensión entre constitucionalismo y democracia. 3 El control judicial como expresión de la tensión entre constitucionalismo y democracia. 4 El constitucionalismo democrático. 5 Los tribunales constitucionales y la democracia. 6 ¿Quién tiene la última (o la única) palabra en la interpretación constitucional? 7 Cómo mantener la autoridad de una misma constitución en una sociedad pluralista. Bibliografía.

\section{INTRODUCCIÓN}

En un análisis sobre el estado actual de los sistemas políticos y el funcionamiento de las democracias latinoamericanas, no resulta infundado afirmar que se atraviesa por malos momentos. Las clases políticas tradicionales, o las nuevas que han conseguido el poder, así como las instituciones públicas en general, gozan de muy poca credibilidad y hay una extendida desconfianza en sus representantes porque actúan con independencia de las necesidades ciudadanas reales (RODRÍGUEZ - SELIGSON, 2011, pp. 49 ss. y GARCÍA VILLEGAS - REVELO, 2009). Una pequeña elite es la verdaderamente beneficiada del progreso mientras que las diferencias sociales se mantienen, cuando no se acrecientan.

Los déficits en la representación real del grueso de la población ante las instancias de toma de decisiones políticas, facilitan la aprobación de medidas parcializadas. Los grupos de interés más poderosos ejercen una indebida influencia sobre el proceso político. Por estas influencias el sistema político en conjunto tiende a sesgarse a favor de cierta ideología o a favor de ciertos grupos, lo que termina menguando el tan importante valor de la imparcialidad en la política. El proceso de toma de decisiones legislativas se coopta muchas veces por intereses políticos sectarios, empresariales y fuerzas de mercado, y es siempre dependiente de la coyuntura impuesta por el cabildeo.

Si bien se ha avanzado en el cumplimiento de criterios básicos propios de regímenes político-democrático, pues en las décadas pasadas eran más los gobiernos autoritarios y no se ven más gobiernos militares que desaparecen a sus opositores ${ }^{1}$, los progresos alcanzados en la democracia electoral no han contribuido con el desarrollo de una democracia real, es decir, una democracia donde se garantizan derechos políticos mínimos (voto, oposición, pluralidad partidista, división de poderes y un sistema de frenos y contrapesos que opere razonablemente bien). Es más,

\footnotetext{
${ }^{1}$ En la década de 1980 de los 18 países incluidos en el informe del PNUD sólo tres podían considerarse democráticos: Colombia, Costa Rica y Venezuela.
} 
el ejercicio de la democracia electoral en muchos contextos signados por la pobreza -que ha disminuido levemente- y la desigualdad -que permanece prácticamente invariable-, ha contribuido a agravar déficits democráticos.

Ciudadanía en situación de necesidad es fácilmente manipulable electoralmente, por lo que funcionarios en cargos públicos de elección popular que aspiran reelegirse, si bien montan una plataforma política y se identifican más o menos con determinada ideología, saben que sobre todo necesitan ingentes recursos para realizar una campaña exitosa. Con obsequios y compra de votos en época preelectoral se consiguen victorias, pero se generan profundos problemas de representación política. El elegido no se siente comprometido con quienes lo eligieron sino con quienes financiaron su campaña. Dentro de esta lógica perversa se contribuye a su vez a agravar otras falencias de las democracias latinoamericanas: la corrupción y el clientelismo.

Sólo al interior de un régimen verdaderamente democrático las sociedades latinoamericanas podrán ser no solo más igualitarias sino también más desarrolladas, pues quienes carecen de niveles mínimos de bienestar y sufren las injusticias de la desigualdad, pueden reclamar, movilizarse y elegir en defensa de sus derechos ${ }^{2}$. Ahora bien, ¿cómo aumentar los grados de representatividad política y de legitimidad democrática del constitucionalismo? Ante un problema ya bien diagnosticado han surgido diversas respuestas posibles. No interesa aquí examinarlas sino señalar una cuestión común a las principales, cual es la necesidad, tanto de una ciudadanía activa en el planteamiento de problemas y alternativas, como de unas instituciones judiciales sensibles o receptivas ante tales expresiones de la sociedad civil organizada, es decir, decisiones que tomen en consideración las perspectivas que, sobre la definición de las disposiciones constitucionales de naturaleza moral, tienen distintos sectores de la sociedad.

Esta cuestión ha sido abordada recientemente por el Constitucionalismo democrático (POST - SIEGEL, 2013), un movimiento de origen estadounidense que, además de teórico, procura contribuir a que el progresismo y el activismo constitucional tengan incidencia efectiva en la práctica política. Al movimiento le interesa, tanto cuestionar que los tribunales encargados de los asuntos constitucionales se han atribuido ciertas facultades que originalmente no les fueron conferidas, como proponer un tipo de rol judicial que, si bien esté orientado por el progresismo, sea sobre todo consciente de que el significado de la constitución y en general del derecho constitucional se configura a partir de interacciones que surgen de una perspectiva dialógica o deliberativa entre diversos actores: el gobierno, el congreso, el tribunal que conoce los asuntos constitucionales, las reivindicaciones de los movimientos sociales y los partidos políticos. Estos

\footnotetext{
${ }^{2}$ Como han sostenido repetidos informes de PNUD.
} 
actores tienen conjuntamente la responsabilidad de hacer cumplir las normas constitucionales y de contribuir a configurar el significado del derecho constitucional. El constitucionalismo contemporáneo debe ser sensible o receptivo a estas instancias porque de esta interacción depende, en últimas, su legitimidad.

Sectores sociales se movilizan para defender determinadas perspectivas constitucionales, las cuales el constitucionalismo debe tener mecanismos para incorporar y aumentar así su legitimidad. Un sistema jurídico, una constitución y una interpretación constitucional que sean sensibles y receptivos ante esa movilización, contribuyen a preservar la autoridad de la constitución en la historia. ¿Cómo articular entonces la aspiración del autogobierno colectivo democrático, con la superioridad de la constitución y la fuerza vinculante de los derechos que consagra?

\section{EXCURSO}

Cada pensador, incluso el más abstracto, está profundamente influenciado por las circunstancias de su propio tiempo. Para entender por qué Maquiavelo, Hobbes o Rousseau escribieron como lo hicieron, debemos saber algo acerca de las condiciones sociales y políticas de su época y sus países, así como de las controversias relevantes entonces.

Plamenatz, Man and Society (Vol. I, p. xv).

Se podría plantear una reserva u objeción acerca de la relevancia de utilizar recursos teóricos provenientes de contextos disimiles, algunas veces radicalmente como el estadounidense, al examinar y contribuir a solucionar realidades como las que acontecen en América Latina.

Esta reserva tiene una idea implícita. Las teorías no nacen en el vacío. Las teorías jurídicas y constitucionales en particular surgen en determinados países para dar respuesta a sus problemas acuciantes. ¿Es fortuito acaso que Alexy hubiera escrito su teoría de la argumentación jurídica y, sobre todo, su teoría de los derechos fundamentales en la Alemania de principios de la década de 1980, cuando no había una sistematización de la jurisprudencia por parte del Tribunal Constitucional Federal? ¿Es casual que Taking Rights Seriously de Dworkin llegara poco después de la Guerra del Vietnam o que Rawls se hubiera manifestado en contra del utilitarismo como el mejor modo de fundamentar políticas cuando acontecían las batallas por los derechos civiles?

En el curso de acontecimientos histórico-políticos y procesos de cambio institucional, hay buenos ejemplos históricos de obras filosóficas que ejercieron influencia en la orientación del pensamiento y en la fundamentación del deber ser de la acción política. San Agustín o Santo Tomás son esenciales para comprender el orden político medieval; Locke o Bacon para la revolución inglesa; Diderot y los enciclopedistas para la Revolución Francesa; Jefferson, Adams y Franklin 
para el proceso de independencia estadounidense; y Marx, Engels y Hegel para la Revolución Soviética. Foucault, Benjamin y Lévi-Strauss fueron pensadores también comprometidos con su tiempo.

Si son indisociables contexto socio-cultural y teoría constitucional, se plantea entonces la reserva ¿es pertinente acudir a la obra de Dworkin, Post o Habermas para analizar los problemas de nuestros contextos a pesar de sus diferencias entre, digamos, sitios de producción y sitios de recepción?

La respuesta es un "sí” condicional. Implica que al momento de abordar una teoría constitucional en un contexto distinto a aquel donde surgió, se deben acometer dos retos: un reto teórico y un reto que llamaría sociológico. El primero tiene que ver con la fidelidad, precisión y rigor con los que se analizan teorías sociales comprendiendo correctamente sus planteamientos centrales y sus principales elementos medulares. Pero dentro del derecho constitucional y la filosofía política, y en contextos como los latinoamericanos, se sustenta que este no es el único reto. Se demanda uno sociológico, es decir, el que procura trascender las teorías de amplia circulación transnacional para ponerlas a hablar en clave de recepción, honrándolas en sí mismas pero problematizándolas respecto a los problemas que ocupan y aquejan las distintas jurisdicciones políticas y sociales - además de académicas - de los países receptores de teorías. Los retos al momento de abordar una teoría influyente de circulación trasnacional para explicar una realidad particular diferente, e intentar transformarla, superan aquellos retos impuestos por la mera erudición.

Al presentarse las teorías transfiguradas y mutadas por los contextos de recepción, se constituyen más factiblemente en alternativas sólidas para hacer realizables ideales normativos. Por ejemplo Rawls justificó, pero también condicionó, el recurso a la abstracción en la filosofía política. Sostuvo que "una concepción política debe ser practicable, esto es, debe caer dentro del arte de lo posible” (RAWLS, 1999, p. 486). Posteriormente expresó la misma idea al decir que

La filosofía política no se aparta, como algunos han pensado, de la sociedad y del mundo [...] el trabajo de abstracción no es gratuito; no se hace abstracción por la abstracción misma [...] Es un error pensar en las concepciones abstractas y en los principios generales como los que siempre pasan por encima, atropellando nuestros juicios más particulares (RAWLS, 1995, p. 64-5).

El reto teórico es sólo entonces un primer momento en el abordaje y la reconstrucción de un determinado modelo democrático o constitucional. Teorías normativas de la democracia y perspectivas constitucionales sustantivas, permiten comprender que la realidad no se debe reducir a lo existente. Que la correcta descripción es un primer momento en la configuración de la adecuada 
prescripción. En una sociedad lo necesario podrá ceder ante lo posible si concebimos que los retos en las obras de los autores canónicos de las teorías democráticas y neoconstitucionales, no están sólo y ni siquiera particularmente en la sofisticación de una interpretación conceptual o en la reconstrucción puramente analítica de una u otra interpretación de uno u otro pasaje de una obra. La validez de una teoría constitucional o de un modelo democrático no se debería probar en la pura abstracción.

Las teorías jurídicas y políticas transnacionales tienen para mucho por enseñarnos, pero se debe también y sobre todo responder al deber de hacerles rendir efectos prácticos para contribuir así mucho más factiblemente a encontrar soluciones a complejos problemas sociales. No hay buena teoría sin investigación empírica ni buena investigación empírica sin teoría y es necesario articular la teoría con la práctica porque es imposible separar las dos dimensiones en la construcción de una buena dogmática jurídica que necesariamente tiene un componente teórico.

Desde el sur global se debe seguir investigando sobre las grandes teorías que integran cánones trasnacionales del pensamiento iusteórico y filosófico-político, pero se debe procurar aprender de ellas para construir mejores teorías intermedias sobre nuestras realidades periféricas. Tenemos que hacer recepciones creativas de las teorías de circulación trasnacional. Hay una diferencia entre adoptar y adaptar una teoría, y por lo que hay que propender es por lo segundo. Debemos crear conocimiento jurídico constitucional propio, crítico, que surja deductivamente a partir del canon teórico trasnacional, de las grandes teorías que circulan entre nuestras redes académicas, pero también inductivamente a partir de las circunstancias que aquejan a nuestras sociedades. Además, las teorías constitucionales nacen a partir de relaciones entre saber y poder, y estas relaciones son muy particulares entre los países. Debemos entonces abrir caminos que permitan la creación de una conciencia jurídica propia que se aleje de la reproducción de conocimiento constitucional producido en otros contextos y la cual tenga en cuenta la naturaleza hibrida de nuestras propias tradiciones jurídicas y nuestra situación y nuestras necesidades.

\section{TENSIÓN ENTRE CONSTITUCIONALISMO Y DEMOCRACIA}

Pocos conceptos integran de manera tan conspicua el vocabulario jurídico-político moderno, como “constitución” y “democracia”. Desde los textos fundacionales del constitucionalismo se ha planteado la muchas veces difícil relación entre una forma de organización política determinada por un texto que ocupa la cúspide de la pirámide normativa, y la forma adecuada de realizar el autogobierno colectivo. El concepto “democracia” hace referencia a una 
doctrina política en virtud de la cual, como señala su bien conocido origen etimológico, el pueblo se autogobierna. Procura una correspondencia entre quienes configuran la ley y quedan a su vez obligados por ella, por lo que se realiza el ideal de gobierno que consiste en la autodeterminación individual y colectiva.

La democracia directa de la polis ateniense no se corresponde con el tipo de democracia existente en las complejas y fragmentadas sociedades contemporáneas. La forma cómo se ha conceptualizado la democracia no hace referencia en realidad al mismo concepto como se edificó en la antigua Grecia y como se conoció en sus desarrollos, por ejemplo, durante el período de la ratificación de la Constitución Estadounidense, la Revolución Francesa o cuando cayó el fascismo.

Un aspecto importante de la relación/tensión entre la democracia y el constitucionalismo se sintetiza en el concepto “democracia constitucional”, que trasciende la noción puramente formal de democracia y el tipo estrictamente procedimental de constitución. Los elementos medulares de la democracia constitucional son aquellos propios de la democracia política (como el derecho al voto igual, el principio mayoritario y la pluralidad de los partidos políticos), y una articulación entre el constitucionalismo clásico liberal y el constitucionalismo contemporáneo (como, de un lado, la regla de mayorías, la división de poderes, la rigidez constitucional y el sistema de frenos y contrapesos institucionales, y, de otro, la naturaleza normativa de la constitución, la fuerza vinculante de los derechos, el control judicial de constitucionalidad, los principios constitucionales de naturaleza moral, la amplia y protegida participación política, la protección de las minorías, la positivización constitucional de los derechos humanos y la configuración jurisprudencial de los derechos fundamentales).

La constitución, entendida desde las perspectivas normativas de la democracia, limita el poder del gobierno y el congreso, pero sobre todo amplía las exigencias a todos los poderes públicos que se encuentran vinculados a los derechos fundamentales. La democracia constitucional significa, de un lado, que el pueblo se debe autogobernar; que la soberanía reside en el pueblo que es quien detenta en últimas el poder político. Pero de otro lado significa también que ese autogobierno, que ese poder, no se puede ejercer de cualquier forma. Si bien en la ley debe estar representada la correspondencia entre quienes la adoptan y quienes la deben cumplir, en la constitución se encuentran normas que se deben cumplir por sobre cualquier circunstancia o consideración. Estas normas son los derechos fundamentales y los principios de naturaleza moral (dignidad humana, igualdad material, justicia social, pluralismo, autodeterminación de los pueblos y solidaridad). 
Después de la ruinosa debacle en que el fascismo sumió a Europa, se procuró rehabilitar el derecho mediante el establecimiento de nuevas garantías ciudadanas y compromisos entre gobernantes y gobernados para romper radicalmente con el pasado reciente. Otra respuesta fue la creación de tribunales constitucionales. Aunque no tienen la posibilidad de convertirse en los garantes súper poderosos de las democracias como muchas veces se les concibe, en virtud del principio de colaboración armónica entre las ramas del poder público para la realización de los fines estatales, no se les puede relegar a un rol de instancia estricta de legislación negativa. Se constituyen en un poder legítimo creador de derecho. La cuestión cardinal es el resguardo jurisdiccional de la democracia constitucional: qué no pueden decidir ni siquiera las mayorías y cómo deben proceder los tribunales constitucionales en casos de violación de derechos fundamentales por cuenta de la inacción o acción insuficiente del Gobierno o el Congreso.

El gobierno sometido al estado democrático de derecho tiene sentido precisamente porque debe tener límites definidos la configuración política de la voluntad (más que mayoritaria) de quienes detentan el poder. Aunque surge una cuestión en principio discutible sobre la necesaria prevalencia de las opiniones de los magistrados sobre las de la opinión pública, particularmente los firmantes de iniciativas legislativas, y los congresistas, la presunción relativa al hecho de que las mayorías deben gobernar, se desestima no sólo porque en las democracias latinoamericanas, y la colombiana en particular, no son las mayorías las que están en las instancias de decisión política, sino porque incluso si así fuera, el propósito de las declaraciones de derechos que se incluyeron en las constituciones luego de la segunda posguerra fue precisamente retirar ciertas cuestiones de las vicisitudes de la cotidianidad política. Madison sostenía que el "trono de la razón” debe estar resguardado de “pasiones mayoritarias” (HAMILTON; MADISON; JAY, 1961, No. LXXVIII).

Al concepto “democracia” se le agregó el adjetivo relacional “constitucional” porque reconocer la máxima validez normativa a los derechos fundamentales y a los principios constitucionales, implica que se constituyen en los límites por donde debe fluir el poder político con toda su fuerza y el cauce para impedir que la voluntad electoral se desborde. La democracia constitucional se distingue de la soberanía popular y del mayoritarismo porque mientras éstas son ideas descriptivas sobre los procedimientos de toma de decisiones, aquella es una idea normativa que se refiere a valores políticos substantivos. La democracia constitucional es una concepción normativa de la democracia porque consagra los principios que nos permiten determinar si en circunstancias específicas los procedimientos de toma de decisiones son realmente democráticos (POST, 2006; vers. cast. en: GARCÍA JARAMILLO, 2014). 
Democracia no sólo significa en la actualidad respeto a la regla de mayorías y resguardo del derecho al voto, sino también respeto a los diques que establecen las constituciones. Además del reconocimiento a la máxima validez normativa a los derechos fundamentales y a principios morales como igualdad material, justicia social, pluralismo, dignidad humana y solidaridad, tales diques son, en tanto elementos esenciales para asegurar la fórmula política del estado democrático de derecho, el respeto por las reglas de juego electoral con la posibilidad real de alternancia en el poder, el sistema de frenos y contrapesos, el principio de igualdad, el goce efectivo de los derechos, los controles interinstitucionales entre las ramas del poder público y el presupuesto de que entre los poderes del Estado debe haber un equilibrio.

Existen instituciones a las que se le confía el fortalecimiento y la conservación de los diques, es decir, tribunales constitucionales que protegen la integridad y supremacía de la Constitución. De un lado, operan como un legislador negativo verificando la constitucionalidad de las leyes y los actos legislativos, sobre todo de aquellos que pretenden reformar parcialmente la Constitución al modificar algunos de sus aspectos esenciales, pero su función también es positiva en sentido proactivo pues, de otro lado desarrolla en casos concretos los postulados que en forma de provisiones y garantías iusfundamentales se reconocen como uno de los fines del Estado.

Fue superada por su propia historia la idea de demos-kratos, es decir, el poder o gobierno del pueblo. Una democracia constitucional debe contar con mecanismos para impedir que la voluntad electoral sea manipulada y que mediante plebiscitos o referendos se generen autoritarismos con amparo popular. El poder judicial resguarda el carácter indisociable de la democracia política y los derechos fundamentales. Un sistema político democrático no se establece con la mera configuración de la voluntad general a través del voto, sino que el modelo normativo de la democracia contemporánea es constitucional porque la expresión popular está atada con un “nudo gordiano” a la proclamación normativa con eficaz garantía de los derechos fundamentales. Ya en 1787 decía Madison que el fin del sistema constitucional es impedir que una sola facción política, que un solo partido o movimiento, se apodere del aparato institucional.

Si por algún aspecto tiene sentido la idea del gobierno sometido a los principios constitucionales, es porque deben establecerse límites a la configuración política de las posiciones respaldadas por algún amplio grupo, es decir, de aquello que las mayorías pueden imponer a las minorías en casos concretos. Esta cuestión se halla entre los aspectos que tradicionalmente mayor resonancia ha tenido en América Latina cuando se aborda aquello que precisamente para resguardar la democracia constitucional no pueden decidir ni siquiera las mayorías. En este sentido hay que comprender las restricciones que imponen al actuar del poder público las constituciones expedidas 
desde la segunda posguerra. Una medida por muy mayoritariamente apoyada que esté, si viola los derechos fundamentales de algún grupo, debe ser invalidada. En casi todos los casos la mayoría, o la facción minoritaria en el poder, sentirá un interés o una pasión comunes que procurará convertir en norma con validez universal. En una democracia constitucional no se pretende que las decisiones de los funcionarios reflejen exclusivamente la voluntad mayoritaria. Acuerdos con amplios apoyos mayoritarios pueden asfixiar una democracia constitucional tanto como un régimen dictatorial (FERRAJOLI, 2007, Parte quarta).

La democracia actual no es ya entonces la mera representación de los intereses del mayor número de personas, como lo entendieron las concepciones agregativa, mayoritaria o populista de la democracia. La democracia en tanto autogobierno y respeto al principio de mayorías significa actualmente también, y sobre todo, respeto a los derechos y principios constitucionales, así como a las reglas de juego democrático. En este sentido se corresponde el cambio contemporáneo del concepto “constitución”, el cual difiere en aspectos sustantivos de aquella concepción de "norma fundamental” sin carácter normativo pleno, que dominó la teoría constitucional por décadas.

En la actualidad las teorías normativas de la democracia han contribuido a transformar la idea de una constitución, como expresa Ferrajoli (2002, p. 203):

\begin{abstract}
Una constitución no sirve para representar la voluntad común de un pueblo, sino para garantizar los derechos de todos, incluso frente a la voluntad popular [...] El fundamento de su legitimidad, a diferencia de lo que ocurre con las leyes ordinarias y las opciones del gobierno, no reside en el consenso de la mayoría sino en un valor mucho más importante y previo: la igualdad de todos en las libertades fundamentales y en los derechos sociales.
\end{abstract}

Las decisiones políticas al interior de las democracias constitucionales pueden adolecer, bien de déficit de representación real mayoritaria por los problemas de representación del grueso de la población ante las instancias de decisión, o bien de ser fiel reflejo de una creencia ampliamente aceptada por la ciudadanía en un momento determinado, pero que vulnera preciados principios constitucionales o derechos fundamentales. Una democracia constitucional no es un régimen que se basa en la tiranía de la validez obtenida por apoyo mayoritario, sino que encuentra su fundamento y razón de ser en un principio mayoritario restringido en aras a la consecución de la legitimidad por la necesidad de propender hacia la satisfacción igualitaria de los intereses de todos. La tiranía mayoritaria se distingue radicalmente de la democracia basada en una constitución, como pensaban los federalistas estadounidenses, Madison en concreto, quien entre otras ideas defendió que uno de los sentidos de tener una norma con superioridad jerárquica respecto de las otras, era dejar ciertos asuntos por fuera de la coyuntura política, uno de los cuales eran ciertos derechos. 
Hay una tensión inevitable entre dos aspiraciones irrenunciables e igualmente valiosas: el autogobierno y el gobierno limitado por los derechos individuales. Los mecanismos contramayoritarios del constitucionalismo conllevan inevitablemente la restricción de uno de nuestros derechos (igual participación en la toma de decisiones públicas). Sin embargo cabe la posibilidad de que se compense por una mejor protección de derechos como aquellos que aseguran la autonomía individual (BAYÓN, 2010, en: CARBONELL; GARCÍA JARAMILLO, 2010). Por trivializarlo periodísticamente: mucha constitución puede conducir al exagerado activismo judicial. Mucha democracia popular conduce fácilmente al populismo exacerbado. Mucho puede lograrse sin duda con una buena constitución, pero poco puede alcanzarse realmente sin la acción política. En los sistemas jurídicos constitucionalizados las democracias necesitan de un Estado de derecho fuerte, pero también que el diálogo constitucional sea fluido y constante. Esta es la premisa del Constitucionalismo Democrático.

\section{EL CONTROL JUDICIAL COMO EXPRESIÓN DE LA TENSIÓN ENTRE CONSTITUCIONALISMO Y DEMOCRACIA}

Ha dejado de ser un asunto controversial el hecho de que las leyes deben están sujetas a algún tipo de control judicial de constitucionalidad. En ello recae parte fundamental de la consideración como constitucional de un sistema democrático, es decir, del hecho de que la voluntad mayoritaria expresada en la ley sea susceptible de examen posterior de forma tal que se verifique su conformidad con los derechos y principios que consagra una constitución ${ }^{3}$. El control constitucional se halla dentro de los atributos de validez y legitimidad del resultado del procedimiento legislativo.

A pesar de lo que se acaba de sustentar acerca de la necesidad de contener constitucionalmente la fuerza de la expresión democrática, compartimos con Bayón, Ferreres y Gargarella, entre otros, que la objeción democrática es relevante. Hay que sofisticar la defensa a la legitimidad del control constitucional afirmando más que consiste en el sometimiento de las mayorías a la constitución. Debe avanzarse hacia la determinación de los aspectos del proceso judicial que lo hacen mejor que el propio proceso político en el congreso para garantizar el respeto a los derechos constitucionales fundamentales. No se trata entonces de una justificación automática que se dé por sentada en el marco de una democracia constitucional.

\footnotetext{
${ }^{3}$ Particular atención presta a esta cuestión la sección III de CARBONELL; GARCIA JARAMILLO, 2010. Con contribuciones de Juan Carlos Bayón, Víctor Ferreres, Rodolfo Vázquez, Gargarella y Gustavo Zagrebelsky.
} 
El control judicial de constitucionalidad supone un costo democrático prima facie, al que autores como Dworkin no prestan mayor atención (DWORKIN, 2014) ${ }^{4}$. La intervención del tribunal en el resultado de la conformación de la voluntad mayoritaria se justifica si se tienen razones de peso para creer que va a generar el beneficio democrático que puede compensar ese costo. En una democracia no está en discusión la importancia de la regla de la mayoría, pues fue diseñada para respetar el derecho a la igual consideración y respeto de los ciudadanos. Pero la igualdad política es más que la regla de la mayoría, pues para honrar aquella muchas veces deben considerarse restricciones a esta. Respecto de la objeción democrática al control judicial, diríamos sencillamente que solo si se piensa en términos de democracia electoral o de principio mayoritario, sería insuperable el costo que implica el control judicial de constitucionalidad.

El tribunal que conoce de los asuntos constitucionales debe ser consciente entonces que su principal actividad, su raison d'etre, como es ejercer el control sobre la conformidad constitucional de las leyes y las reformas constitucionales, implica un costo democrático que se debe ponderar con el beneficio resultante de dicho control. De ahí que diseñe o acate propuestas acerca de mecanismos para aumentar su sensibilidad con las perspectivas constitucionales de la sociedad civil.

La forma para conseguir que los tribunales sean democráticos no es repitiendo experiencias desafortunadas como la boliviana donde se vota por la elección de magistrados. Los tribunales no deben tratar de convertirse en instituciones democráticas como son los parlamentos, sino que se deben articular en un todo que es globalmente democrático. El diseño de mecanismos que reduzcan la tensión entre la justicia constitucional y la democracia es la forma de superar el costo que supone el control constitucional. A esto nos dirigen las dos primeras de las tres condiciones democráticas que sugiere Dworkin para garantizar a las personas su igual pertenencia a la comunidad política: cada persona debe tener la oportunidad de incidir en el contenido de las decisiones colectivas, sus intereses deben ser tenidos en cuenta con igual consideración y se le debe dejar en libertad para elegir el tipo de vida que le resulte más valiosa ${ }^{5}$.

La relación entre la legitimidad del control constitucional y el Constitucionalismo Democrático, y por ende su contribución a la superación de al menos una expresión de la tensión entre constitucionalismo y democracia, radica en el valor deliberativo y participativo de la democracia. La propuesta radica entonces en defender el control constitucional a pesar del costo

\footnotetext{
${ }^{4}$ Otros autores restringen el control constitucional a determinados casos. Ely, por ejemplo, concentra la justificación del control judicial en las situaciones cuando el legislador: (1) restringe los derechos en virtud de los cuales se reputa como genuinamente democrático el proceso político, es decir, cuando se afecta de algún modo el derecho a participar en política (libertad de expresión, voto...) o cuando (2) se sufren discriminaciones en la distribución de cargas y beneficios sociales (ELY, 1980, p. 74).

${ }^{5}$ DWORKIN, Ronald. Freedom's Law. Cambridge: Harvard University Press, 1996, p. 24-6.
} 
democrático que implica si el proceso judicial encuentra formas de considerar en sus razonamientos las perspectivas de la sociedad civil organizada. Si el sistema cuenta con una válvula de escape para escuchar a quienes sustentan posturas constitucionales diversas al momento de dotar de contenido y configurar una determinada disposición constitucional.

\section{EL CONSTITUCIONALISMO DEMOCRÁTICO}

El Constitucionalismo Democrático (“Democratic Constitutionalism”) aborda una cuestión de acuciante vigencia en el contexto de la práctica del derecho constitucional estadounidense, pero que está en capacidad de rendir importantes efectos teóricos, doctrinarios, pedagógicos y jurisprudenciales en distintos contextos iberoamericanos en los cuales pareciera, de un lado, respecto del poder judicial, que los magistrados de las altas cortes han monopolizado la interpretación constitucional y, de otro, respecto de la sociedad civil, que el progreso social se puede alcanzar fundamentalmente ante la sede judicial y sin responder a la movilización política.

Hace parte de uno de los desarrollos teórico-políticos más importantes en el constitucionalismo estadounidense de los últimos 20 años ${ }^{6}$. Surge con la pretensión de reorientar el destino del constitucionalismo luego del viraje conservador y retardatario que tuvo a partir del gobierno Reagan (1981-1989). Académicos progresistas dentro de los que se encuentran Robert Post, Reva Siegel y Jack Balkin (Yale), así como Mark Tushnet (Harvard) y Larry Kramer (Stanford) ${ }^{7}$, al evidenciar el avance y los éxitos conseguidos por la agenda política conservadora en las maneras prevalentes de interpretar y configurar el derecho constitucional, tomaron una postura más proactiva a este respecto.

Refleja una inconformidad radical con la forma contemporánea de concebir el derecho, arraigado en concepciones conservadoras que en Estados Unidos constituyen el legado que el gobierno de Reagan se propuso instaurar. Esa agenda contribuyó a configurar jurídica y socialmente el derecho constitucional. Profesores e investigadores conocieron unos documentos del Departamento de Justicia, titulados “La Constitución en 2000”, que fueron redactados en 1988 durante el gobierno Reagan. Este proyecto para cambiar el derecho constitucional procuró, con un éxito estimable, instaurar en varios niveles jurisdiccionales una práctica jurídica conservadora que

\footnotetext{
${ }^{6}$ Dentro de las obras representativas del movimiento, se destaca BALKIN; SIEGEL, 2009.

${ }^{7} \mathrm{Si}$ bien habría diferencias entre el constitucionalismo popular, que suscriben Kramer y Tushnet, y el constitucionalismo democrático, no interesa en este momento plantear la distinción. Sobre el primero, véase GARGARELLA, Roberto. Una disputa imaginaria sobre el control judicial de las leyes. El "constitucionalismo popular” frente a la teoría de Nino. En: CARBONELL, Miguel; GARCÍA JARAMILLO, Leonardo (Ed.). El canon neoconstitucional. Bogotá: Universidad Externado, 2010; 2. ed., Madrid: Trotta, 2010.
} 
estuviera orientada, básicamente, por formas particulares de litigio y por designaciones para el poder judicial. Los movimientos sociales y políticos conservadores no ahorraron esfuerzos ni recursos para hacer que el constitucionalismo concordara con sus perspectivas sobre los derechos y sobre la organización del gobierno.

Este proyecto político se desarrolló mediante determinadas elecciones e interpretaciones de la constitución, en virtud de la cual se identificaron precedentes importantes que debían conservarse o modificarse según hubieran sido, desde su filosofía judicial, correcta o incorrectamente decididos de acuerdo con criterios como la estricta interpretación constitucional conforme al significado original. Dentro de los segundos se destacan precedentes relacionados con casos como la separación entre iglesia y Estado, el aborto, los métodos anticonceptivos, la educación sexual en las escuelas, el poder ejecutivo, el derecho a la intimidad, la protección constitucional de los acusados en casos penales y cuestiones de raza e igual protección, federalismo y poder legislativo para promulgar leyes sobre derechos civiles. Los conservadores les enseñaron a los progresistas que la acción política, en lugar de la estrictamente jurídica, es esencial para configurar el derecho constitucional mediante la incorporación de determinada ideología en el proceso de interpretación constitucional.

El Constitucionalismo Democrático defiende un original proyecto en virtud del cual se debe implementar a futuro una perspectiva duradera del progresismo en el derecho constitucional, orientando las cuestiones más acuciantes del debate. Desde este modelo teórico se aboga por una nueva perspectiva en las polémicas tradicionales por las relaciones entre el constitucionalismo y la democracia. Cada uno de estos dos pilares de las sociedades contemporáneas comporta una serie de valores y principios que suscitan tensiones cuando se tratan de armonizar en la vida en comunidad. Los tribunales son entidades democráticas y el poder judicial es un poder político porque versa sobre la integridad y supremacía del texto político por excelencia: la constitución política. Propone una serie de temas, argumentos y discusiones que podrían apoyar una revalorización en el contenido de la discusión constitucional iberoamericana. Se analizan desde diversas perspectivas las formas como se legitima popularmente el derecho constitucional, toda vez que las interpretaciones monopólicas del texto por parte de los jueces y que las normas proferidas por el poder legislativo, no son necesariamente suficientes para dotar de legitimidad a la normativa constitucional. En las reacciones ciudadanas vehementes es donde la integridad del estado de derecho colisiona con la necesidad de que los ordenamientos constitucionales cuenten con legitimidad democrática (POST; SIEGEL, 2007; vers. cast. en: POST; SIEGEL, 2013).

En la consolidación de la democracia y en el progreso social los tribunales desempeñan un rol crucial, el cual en algunos casos es subsidiario. El cambio constitucional debe fluir desde abajo 
en lugar de ser unilateralmente impuesto desde arriba, en especial si pretende ser democrático. En el nivel local se construyen consensos políticos que luego son amparados judicialmente en el nivel constitucional. Con sus decisiones sensibles a la democracia los tribunales muchas veces impulsan a la sociedad hacia un rumbo determinado. El cambio constitucional debe ser dialéctico e interactivo porque las ramas del poder público deben promover conjuntamente los valores constitucionales progresistas. Las reformas jurídicas no necesariamente erradican la injusticia, pero con frecuencia contextos y situaciones injustas se reconfiguran para prosperar en nuevos ambientes jurídicos (SIEGEL, 1997).

El Constitucionalismo Democrático es un modelo de teoría del derecho con profundas implicaciones políticas. Puede contribuir a la tarea de fundamentar una concepción liberal de la jurisprudencia y una práctica judicial progresista, duradera y públicamente justificable. Otorga elementos que pueden contribuir en la esfera doctrinaria, académica y política en los intensos debates que se desarrollan en la actualidad sobre los diversos temas que vincula el amplio campo del derecho constitucional, en particular, la acción política y el compromiso con un sistema jurídico legítimo en el cual todos podamos reconocernos como partes.

El gobierno, el congreso y el tribunal que conoce de los asuntos constitucionales tienen la responsabilidad conjunta de hacer cumplir las provisiones iusfundamentales establecidas en la norma que cuenta con la máxima validez formal, porque ocupa la cúspide de la pirámide normativa en los países que optaron por el constitucionalismo como forma de organización jurídico-política. Si el derecho constitucional se enfoca exclusivamente desde la perspectiva de los tribunales, se tiende a perder de vista este aspecto, así como el hecho de que su legitimidad democrática radica, de modo fundamental, en que las sentencias surgen no sólo de estrictos razonamientos judiciales, sino también de interacciones entre el poder judicial y las otras ramas del poder público, las asociaciones civiles, los partidos políticos, los organismos de control, los movimientos sociales, la opinión pública, los centros de investigación y el poder judicial en conjunto ${ }^{8}$. A estos escenarios se les debe prestar atención al momento de proferir sentencias ambiciosas o que ejerzan un considerable impacto social. En los sistemas jurídicos constitucionalizados, las democracias necesitan de un Estado de derecho fuerte, pero también que el diálogo constitucional sea fluido y constante.

El Constitucionalismo Democrático no es una teoría en sentido estricto. Es una concepción general o una idea amplia (KRAMER, 2007) según la cual las altas cortes deben tener capacidades para reflejar e incorporar en sus fallos las perspectivas constitucionales de diversos organismos

\footnotetext{
${ }^{8}$ Sobre la relación entre la legitimación democrática y la necesidad de las personas de poder expresarse, así como sobre la “experiencia del Estado como receptiva a sus propios valores e ideas”, véase POST, 1997, 2006.
} 
democráticos, con el fin de configurar de manera conjunta el significado del derecho constitucional mediante un diálogo constructivo.

Dentro de la academia jurídica sólo recientemente han tomado real importancia las interpretaciones, los argumentos y las discusiones constitucionales, así como las expresiones críticas y propositivas que, sobre el contenido del derecho constitucional, tienen los ciudadanos por fuera de las cortes. Estas resignificaciones y refiguraciones en el derecho constitucional también ejercen influencia en su significado dentro de las cortes. La Constitución, y el derecho constitucional en general, tienen una existencia que trasciende los muros de los tribunales. Las posiciones que se adoptan respecto del significado de determinada norma ante un nuevo y polémico caso (si la igualdad ampara a los afro-descendientes de ciertas discriminaciones o si el tipo actual de matrimonio debe ser o no ampliado para incluir a los homosexuales, por ejemplo), suscitan discusiones que son las que al final dotan al resultado, al fallo, de la legitimidad que no sólo es necesaria para que la decisión sea bien recibida por la comunidad sino también para su efectividad.

El progresismo por el que aboga el Constitucionalismo Democrático es dialógico. Si bien los tribunales tienden puentes entre la normativa constitucional y la realidad social, deben hacerlo conscientes de la importancia de dicha interacción. La forma más adecuada como los tribunales desempeñan su función institucional es articulándose como partes en un extenso diálogo, en virtud del cual responden no sólo al estado de derecho y los principios de legalidad y seguridad jurídica, sino también ante las perspectivas populares de los valores constitucionales. Contribuyen así a la incorporación de tales valores al derecho. Los valores fundamentales que los jueces interpretan y hacen valer hacen parte del consenso político en el que descansa la constitución (FERRERES, 2007). En una sociedad democrática caracterizada por un pluralismo de visiones del buen vivir desde lo religioso, cultural, político y social, los tribunales deben desarrollar actualmente muchos de los fines que persiguió la Corte Warren (1953-1969) en cuanto a los derechos a la igualdad, la justicia social y la acción afirmativa, pero a partir de una jurisprudencia menos centrada en sí misma y más en conexión con movimientos políticos progresistas.

La posibilidad permanente de contribuir a configurar su significado permite comprender por qué permanecen fieles a la constitución los ciudadanos cuyas perspectivas sobre el derecho no son las que imperan. El Constitucionalismo Democrático otorga herramientas para comprender las maneras como la constitución inspira lealtad a pesar del intenso desacuerdo sobre su significado (POST; SIEGEL, 2004; vers. cast. en: POST; SIEGEL, 2013). El pluralismo como uno de los valores propios y distintivos de las sociedades democráticas contemporáneas se reivindica permanentemente al considerar abierto el pacto constitucional (HABERMAS, 1998). Quienes 
defienden el Constitucionalismo Democrático suscribirían el cambio en la metáfora sobre la democracia que propone Obama (2006), a saber, que no es una casa que hay que construir, sino una conversación que hay que mantener.

Los liberales defensores de una configuración progresista del derecho constitucional, deben sofisticar sus análisis y sus apologías al rol y a la importancia de los tribunales en las democracias constitucionales. Deben sobre todo tomar conciencia de que la influencia efectiva que puedan llegar a ejercer en la configuración del derecho constitucional, también les exige un activo involucramiento en la acción política, tal como hicieron los republicanos durante el gobierno de Reagan, en el diseño de sus programas electorales, en la apelación a la opinión pública y en el apoyo electoral a candidatos a corporaciones públicas (presidente, congresistas...) cuyas perspectivas morales y jurídicas concuerden con las suyas.

Si bien cuando las cortes elevan a rango constitucional un determinado derecho ello implica que se le reduce en alguna medida el margen de acción al legislativo en la configuración de la naturaleza o la estructura del derecho, aquellas pueden de igual forma trasformar la política al motivar a las partes en contienda para que dediquen tiempo y esfuerzo a la movilización política con miras a defender determinada interpretación constitucional. Esta idea parte de concebir, en contra de las perspectivas originalistas de la interpretación constitucional, al derecho como un organismo viviente (STRAUSS, 2010).

En este contexto se ha utilizado una falsa dicotomía para caracterizar a quienes defienden el progresismo constitucional ${ }^{9}$. Los constitucionalistas deben ser presuntamente anti-corte o prosustantividad judicial. Post y Siegel argumentan en cambio que toda posición progresista que se enmarque en un garantismo constitucional entraña un compromiso simultáneo con valores particulares y con arreglos institucionales que los protejan en la práctica. Los partidarios del Constitucionalismo Democrático afirman la importancia de que el poder judicial resguarde el carácter indisociable entre la democracia política y los derechos fundamentales, y de que los derechos puedan ser garantizados por vía judicial, pero insisten en que no hay una única sede en el proceso de garantizar los derechos y de interpretar la constitución, y que mucho menos esa sede la representan las altas cortes del poder judicial.

El movimiento no sólo tiene pretensiones descriptivas, sino también prescriptivas. No sólo examina cómo la comprensión popular del derecho constitucional afecta o influye en realidad sobre sus significados y sobre sus contenidos definitivos. Interesa observar cómo los movimientos sociales y políticos, así como los debates públicos sobre la interpretación de la Constitución que se

\footnotetext{
${ }^{9}$ Tal como hace BARRON, 2006.
} 
desarrollan por fuera de las cortes terminan teniendo influencia en el significado que, dentro de las cortes, se le otorga a la Constitución. Pero interesa sobre todo defender que los ciudadanos deben tener un rol más activo políticamente en los distintos contextos en los cuales se configura el contenido del derecho constitucional.

Tiene asimismo un componente crítico que resulta particularmente relevante para la discusión constitucional latinoamericana. El poder judicial no ha sido en general objeto de críticas por parte de la academia jurídica en los países de la región, la cual se ha abocado, en cambio, casi de manera exclusiva, a criticar los poderes ejecutivo y legislativo por sus excesos de poder y sus problemas de corrupción, ineficiencia y carencia de representatividad real del grueso de la población. Es poco conveniente que los doctrinantes del derecho constitucional tengan una deferencia en muchos sentidos acrítica hacia las altas cortes, y Post y Siegel enfatizan las implicaciones que ello tiene para la interpretación colectiva del derecho constitucional.

La idea de un Constitucionalismo Democrático tiene relación directa tanto con la implantación de democracias constitucionales como con la constitucionalización de los sistemas jurídicos que, con diferencias contextuales, se ha venido llevando a cabo en las dos últimas décadas en varios países latinoamericanos. Dentro de los principios esenciales que sustenta la concepción de la democracia constitucional, se destacan además del reconocimiento a la máxima validez normativa de los derechos fundamentales y a principios morales como igualdad material, justicia social, pluralismo, dignidad humana y solidaridad, el respeto por las reglas de juego electoral con la posibilidad real de alternancia en el poder, la salvaguarda del pluralismo político, el sistema de frenos y contrapesos, el goce efectivo de los derechos, los controles interinstitucionales entre las ramas del poder público y el presupuesto de que entre los poderes del Estado debe haber un equilibrio y una colaboración armónica para la realización de los fines estatales. Por mayoritarias que sean las medidas políticas, si exceden estos principios que constituyen los diques por donde debe fluir el poder político con toda su fuerza, la medida debe ser invalidada por el poder judicial, así se lo juzgue como elitista y “antidemocrático”.

Aunque surge una cuestión, discutible en principio, sobre la necesaria prevalencia de las opiniones constitucionales de los magistrados sobre las del pueblo, la presunción relativa al hecho de que las mayorías deben gobernar sin limitaciones a su voluntad se desestima porque en las democracias latinoamericanas no son las mayorías las que están en las instancias de decisión política, sino pequeños pero poderosos grupos, y porque incluso si así fuera el propósito de las declaraciones de derechos que se incluyeron en las constituciones luego de la segunda posguerra, fue precisamente retirar ciertas cuestiones de las vicisitudes de la coyuntura política. Madison 
sostenía que el “trono de la razón” debe estar resguardado de “pasiones mayoritarias”. Una de las condiciones necesarias para hacer realidad el respeto y la vigencia de los derechos fundamentales tiene que ver con la debida delimitación de los espacios de acción institucional entre los jueces constitucionales y el legislador como representante de la voluntad popular. Los principales problemas de justificación del constitucionalismo surgen al asumir el valor de la democracia y reconocer el principio mayoritario como uno de sus elementos.

\section{LOS TRIBUNALES CONSTITUCIONALES Y LA DEMOCRACIA}

Un rasgo significativo de la política en América Latina en las últimas dos décadas ha sido su judicialización, la cual ha otorgado particular e inédito protagonismo al poder judicial. Ha acontecido un creciente protagonismo de las altas cortes en temas políticos, ya que muchos asuntos que tradicionalmente eran decididos por medios políticos, y que se consideraban propios de la arena política, son ahora decididos por los jueces. Las altas cortes locales y los tribunales internacionales de justicia, edifican márgenes de configuración constitucional desde la protección de los derechos fundamentales y crean controles de distintas intensidades para el ejercicio de la función pública. La constitucionalización del derecho ha derivado en una progresiva judicialización de la política, porque cuando los derechos y principios irradian íntegramente la estructura del poder público debido al deber de interpretar toda la normativa conforme a la constitución, se limita la soberanía del legislador y de los parlamentos y se obliga a todas las instituciones a seguir los dictados constitucionales. Respecto de cómo ha sido en Colombia, en México, Ecuador y Chile la judicialización de la política ha sido débil. Además de la intensidad difieren los procesos de judicialización en la forma, pues en Colombia ha sido sobre todo trabajo de la Corte Constitucional en general, y de la Corte Suprema de Justicia en los casos de investigación y juzgamiento de congresistas o de examen a la legalidad de solicitudes de extradiciones, mientras que en Brasil ha sido el poder judicial en general o en Argentina ha habido un importante papel de la ciudadanía que se manifiesta en paros y marchas (SIEDER; SCHJOLDEN; ANGELL, 2008).

Los jueces, al llevar la constitución a todas las áreas del derecho, han influenciado de manera directa las relaciones políticas. Adicionalmente, por la desidia de los congresos y los gobiernos en cuanto al amparo de derechos fundamentales, sobre todo de las minorías (mujeres, homosexuales, discapacitados, presos, entre otros), las cortes han debido proferir decisiones garantistas y progresistas que han tenido un impacto político y cultural e incluso fiscal, por lo cual se han agregado nuevas y complejas variables a la discusión constitucional latinoamericana. Las 
preguntas en este punto que vincula el Constitucionalismo Democrático son: ¿cuál es la función que las altas cortes le deben prestar a la ciudadanía? ¿Resulta al respecto relevante la consideración de que sus magistrados no son elegidos sino nombrados? ¿En qué institución del poder público radica la sede de la voluntad general? ¿Cuáles restricciones, si es que hay algunas, son admisibles en la configuración de la voluntad general en una democracia constitucional? Si la independencia judicial es un pilar de la democracia, ¿cuál debe ser el grado de deferencia, si es que debe haber alguno, de las altas cortes hacia el pueblo?

Tras estas cuestiones están presentes temas propios no sólo del constitucionalismo, sino del estudio científico de la política, campos en cuya área de intersección se ubica el Constitucionalismo Democrático. Un problema central en estos campos es el rol de los tribunales constitucionales ante dos tipos de situaciones: las normas proferidas por el congreso que vulneran principios constitucionales, y el déficit amplio y generalizado en la garantía de derechos fundamentales que fuerza a las cortes a adoptar un rol progresista en el diseño de remedios institucionales que contribuyan a solucionar dichas violaciones, lo cual termina necesariamente por ensanchar jurisprudencialmente el contenido normativo de la propia constitución. Una de las principales características de los ordenamientos jurídicos constitucionalizados es la ampliación de la densidad normativa material de la constitución por cuenta de las sentencias que, en la resolución de casos concretos, interpretan y concretan los principios y derechos constitucionales, a partir de lo cual se constituyen subreglas jurisprudenciales que, a su vez, crean una red de precedentes con los cuales, fundamentalmente, las altas cortes contribuyen en el proceso de la creación y el desarrollo del derecho.

Se han presentado varias objeciones a estas situaciones por no ser democráticas o por ser incluso antidemocráticas. No es este claramente el lugar para repasarlas, pero interesa enfatizar que debido a los márgenes constitucionales que tienen las democracias contemporáneas, una institución debe asumir el rol de controlar que las mayorías respeten el pacto constitucional. La idea de democracia constitucional preceptúa sobre todo que una democracia no es un régimen que se basa en la tiranía de la validez obtenida por apoyo mayoritario, sino que encuentra su fundamento y razón de ser en un principio mayoritario restringido en aras a la consecución de la legitimidad por la necesidad de propender hacia la satisfacción igualitaria de los intereses de todos. La democracia, desde que se dejó de pensar sólo en la configuración de la voluntad general, cuenta dentro de sus elementos esenciales la posibilidad de que las distintas facciones puedan llegar a tener juego dentro de la institucionalidad. 


\section{6 ¿QUIÉN TIENE LA ÚLTIMA (O LA ÚNICA) PALABRA EN LA INTERPRETACIÓN CONSTITUCIONAL?}

El Constitucionalismo Democrático no adscribe a las concepciones populista ni agregativa de la democracia, para las cuales las mayorías deben tener la última palabra en la configuración de las políticas, ni rechaza la revisión judicial de constitucionalidad. No objeta la posibilidad de que los jueces ejerzan un poder considerable al controlar la conformidad con la constitución de las leyes expedidas por el congreso y, en general, de los actos de los poderes públicos, garantizando así no sólo la integridad y supremacía del texto fundamental, sino también la vinculación de los organismos estatales a los derechos fundamentales. Sin embargo, Post y Siegel introducen y enfatizan la distinción entre control judicial de constitucionalidad y supremacía judicial; entre la posibilidad de que un tribunal tenga la última palabra y la posibilidad de que tenga la única palabra.

Kramer aborda la distinción entre la supremacía judicial y la revisión judicial de constitucionalidad de las leyes, las cuales por décadas tendieron a considerarse dos caras de la misma moneda, debido sobre todo a la sentencia Marbury vs. Madison (1803) que fundamentó primeramente la facultad judicial para revisar la conformidad constitucional de las leyes y los actos del ejecutivo (KRAMER, 2004). Una de las principales características del sistema jurídico estadounidense es la Judicial Review, extendida ya en los países en los cuales se promulgaron democracias constitucionales, que consiste en la facultad judicial para revisar la conformidad con la Constitución de las normas expedidas por el Congreso y el Gobierno, pudiendo por tanto declararlas invalidas o sometiendo su interpretación a un sentido determinado. En Marbury se instruyó la posibilidad de intervención judicial como mecanismo de realización de la Constitución ${ }^{10}$.

Además de establecer y fundamentar dicha facultad judicial el fallo ubicó la perspectiva del magistrado Marshall sobre la del presidente Jefferson, actuando así como un verdadero poder político del Estado. Casi simultáneamente surgió la perspectiva departamentalista según la cual la supremacía judicial es relativa y debe mediarse con las otras ramas del público en la aplicación de la Constitución. Ninguna de las ramas del poder, ni la judicial, debe tener el monopolio de precisar el significado definitivo de la Constitución. La interpretación constitucional por parte de las altas cortes es autoritativa más no autoritaria, es decir, constituye una de las voces, y no la única ni necesariamente la principal, en el intenso diálogo del cual debe surgir en últimas el significado del derecho constitucional que encuentra entonces su legitimidad en la cultura constitucional de los actores no-judiciales. Respecto de su superioridad jerárquica, en varios casos la Corte Suprema se ha visto abocada a definir y reafirmar la supremacía del poder judicial, y suya en particular,

\footnotetext{
${ }^{10}$ Sobre el caso, consúltese CLINTON, 1989 y NELSON, 2000.
} 
respecto de su poder último en materia jurisdiccional. En Martin vs. Hunter's Lessee (14 U.S. 304, 1816), la Corte sentó por primera vez un precedente en el cual reafirmó no sólo en este caso sino en general su autoridad definitiva sobre las cortes supremas estatales, no obstante tratarse de un país integrado por estados con márgenes significativos de independencia, en asuntos de derecho federal $^{11}$.

Casi simultáneamente al fallo Marbury, surgió la perspectiva departamentalista según la cual podría decirse que, tanto en los sistemas de corte suprema que conoce de asuntos constitucionales como en los sistemas de corte constitucional independiente, la supremacía judicial es relativa y debe mediarse con las otras ramas del poder público en la aplicación de la normativa constitucional. Ninguna de las ramas del poder, incluyendo la judicial, debe tener el monopolio de precisar el significado definitivo de la constitución. La interpretación constitucional por parte de las altas cortes es autoritativa más no autoritaria, es decir, constituye una de las voces, no la única ni necesariamente la principal, en el diálogo del cual debe surgir en última instancia dicho significado, que encuentra entonces también su legitimidad en la cultura constitucional de los actores no judiciales.

No hay razón, además de la normativa orgánica que la ubica como un tribunal de cierre jurisdiccional, que sustente el hecho de que los juicios que las cortes hacen sobre la interpretación constitucional deban situarse necesariamente por sobre los juicios de los otros actores jurídicos y políticos. En la actualidad no se venera con la misma solemnidad la sabiduría que antes se predicaba de los magistrados, en parte porque, como afirman Balkin y Levinson respecto del contexto estadounidense - cómodamente trasladable al latinoamericano -, la mayoría de las veces las sentencias son redactadas por auxiliares recién egresados de las facultades de derecho. Incluso se ha sostenido que los pronunciamientos de la Corte Suprema no son en todos los casos interpretaciones autorizadas del más genuino significado de la constitución (LEVINSON, 1988, p. 9-53 y PAULSEN, 1994, p. 217, 220-2).

Los tribunales no deben tener la última (y, en todo caso, nunca la única) palabra en cuestiones de interpretación constitucional, máxime ante casos complejos de progreso social. En una democracia, el constitucionalismo limita y empodera al gobierno para garantizar los fines del Estado. En lugar de definir la naturaleza y el alcance de los derechos constitucionales desde una torre de Babel donde los tribunales no hablan con los organismos estatales, el Constitucionalismo

\footnotetext{
${ }^{11}$ Posteriormente, en materia de interpretación en particular, profirió la sentencia Cooper vs. Aaron (358 U.S. 1, 18, 1958) donde confirió a su jurisprudencia carácter vinculante a este respecto y en caso de control de constitucionalidad.
} 
Democrático propugna una concepción conforme a la cual la realización de las provisiones constitucionales adquiere su legitimidad y su efectividad como producto de un diálogo progresivo.

Kramer sostiene respecto de la Corte Suprema Estadounidense algo que podría traslaparse al contexto de la Corte Constitucional Colombiana, y es que se trata de

una élite social a la que injustificadamente se ha atribuido una competencia suprema y su supremacía es un indeseable elemento aristocrático que vulnera el sistema democrático. Si la Constitución ha sido creada por el pueblo entonces el pueblo mismo y no la Corte es el que debería tener la supremacía para interpretarla (KRAMER, 2004) ${ }^{12}$.

Para que el constitucionalismo tenga éxito en un contexto de progresismo judicial, debe ser democráticamente legítimo, tiene que reflejar nuestros valores y la forma en la cual entendemos sus profundos significados. A través de las movilizaciones sociales y de la expresión de las posiciones políticas por parte de grupos no institucionales, las personas realizan demandas concretas sobre lo que esperan que sea constitucionalmente amparado o prohibido, sobre la validez que legisladores y jueces deben darle a un significado particular de la constitución, y sobre los cambios que debe tener el derecho constitucional para responder a un mundo interconectado y en permanente cambio (POST; SIEGEL, 2007).

\section{CÓMO MANTENER LA AUTORIDAD DE UNA MISMA CONSTITUCIÓN EN UNA SOCIEDAD PLURALISTA}

En una sociedad pluralista ${ }^{13}$, donde se suscriben diversas concepciones del bien y del buen vivir, y ante constituciones que amparan numerosos derechos, valores y principios de contenido indeterminado, es imposible que las perspectivas de todos los grupos que sostienen posturas diversas (en temas como el aborto, la eutanasia, los derechos diferenciados...) reciban respaldo en una decisión constitucional.

Por esto en las sociedades que optaron por el constitucionalismo como forma de organización jurídico-política, se impone la necesidad de vivir bajo una misma constitución pero al tiempo respetar el pluralismo en el contexto de decisiones que, en casos moralmente complejos, respaldan las perspectivas de unos grupos en demérito de las de otros.

\footnotetext{
${ }^{12}$ Han planteado influyentes críticas similares WALDRON, 2006 y TUSHNET, 2008.

${ }^{13}$ Es decir, donde no solo se reconoce el "hecho del pluralismo" (la constatación incuestionable de que en la actualidad las sociedades democráticas contemporáneas se caracterizan por una diversidad, y en algunos casos incompatibilidad, de doctrinas razonables o concepciones del buen vivir, del orden filosófico, religioso y moral) sino que se valora como un aspecto positivo de las sociedades contemporáneas donde las doctrinas diversas, si son razonables, se respetan y se impulsa su desarrollo (RAWLS, 1993, 1999).
} 
La pregunta es entonces cómo mantener el interés de los grupos sociales, cuyas perspectivas constitucionales no son las que prevalecen, en la organización y la movilización política. Cómo impedir que la frustración ocasionada por el triunfo de quienes sostienen posiciones que difieren con las propias, derive en descontento, apatía y desconexión con la suerte del derecho constitucional.

En la práctica vemos que las discusiones que se desarrollan sobre el significado de la constitución, han contribuido a configurar el contenido del derecho constitucional. En América Latina contamos con buenos ejemplos acerca de cómo importantes elementos del derecho constitucional han evolucionado en respuesta a perspectivas constitucionales sustantivas producto de la movilización de distintos grupos: los homosexuales en Argentina y Colombia, los indígenas en Ecuador y Bolivia, y los estudiantes en Chile, entre otros ${ }^{14}$.

Considerando entonces la importancia de la movilización de los distintos sectores políticos e ideológicos al interior de la sociedad civil organizada, surge la pregunta por cómo mantener su interés en asuntos constitucionales cuando unos salen derrotados y otros victoriosos. La respuesta se halla en el centro de la propuesta del Constitucionalismo Democrático, e incluso explica el concepto que denomina al movimiento. El sistema político y judicial en particular tiene que desarrollar una perspectiva constitucional que resulte suficientemente motivadora y confiable para la sociedad civil, para que actúe a favor de sus intereses a partir de ella. De esto depende la capacidad para expresar esa perspectiva constitucional en términos del derecho ${ }^{15}$.

Lo que mantiene motivados a los grupos que se manifiestan respecto de una u otra perspectiva constitucional, es la posibilidad de que los valores que reivindican puedan en un momento determinado ser considerados y ejercer influencia en aquellos valores que triunfan al momento de otorgarle significado a una determinada disposición constitucional.

Crear y mantener abiertos canales deliberativos entre el tribunal que conoce de los asuntos constitucionales y la opinión pública organizada, permite que se crea en la posibilidad de persuasión recíproca. Además de la mayor legitimidad que alcanzaría una decisión tomada luego de un proceso de planteamiento de argumentos y contestación de contraargumentos, las actividades que podrían desarrollarse a partir de estos canales, o "válvulas de escape”, permitirían tanto que entre la ciudadanía se cree una dinámica política activa frente a ciertos temas como que se asuma que a

\footnotetext{
${ }^{14}$ En Estados Unidos un buen ejemplo lo proporciona el movimiento feminista. Apenas hasta después de la década de 1970 se dejó de concebir como naturales las diferenciaciones sobre la base del sexo. La cláusula de igual protección de la Decimocuarta Enmienda no se interpretaría más como si permitiera la discriminación sexual en parte fundamental por movimientos civiles que se unieron en la lucha contra la legitimidad de estas formas tradicionales de comprender la Constitución. "La discriminación debida al sexo empezó a parecer irrazonable”.

${ }^{15}$ POST; SIEGEL, op. cit.
} 
partir de audiencias públicas o mediante la solicitud de intervenciones públicas en los casos, la corte pueda eventualmente acoger un argumento o respaldar una postura. Esta posibilidad es la que permite que la ciudadanía se mantenga activa y que contribuya así a configurar el contenido del derecho constitucional. Así se preserva la autoridad de la constitución a pesar del desacuerdo ${ }^{16}$. A esto es a lo que Post y Siegel se refieren como la confianza en la "sensibilidad" del ordenamiento constitucional.

La justificación del control de constitucionalidad, y así la mejor forma de distensionar la relación entre el constitucionalismo y la democracia, radica en un cálculo instrumental, es decir, en un cálculo que nos de mayores razones prácticas de peso para suscribir una institución judicial que tiene un coto democrático. Por esta razón se deben diseñar mecanismos para que el tribunal sea sensible o receptivo ante las perspectivas constitucionales de la sociedad, el cual sea sobre todo adecuado a las circunstancias políticas, sociales, culturales y jurídicas de cada país. Además de las audiencias públicas y los amicus curiae, la posibilidad de que la ciudadanía, organizada en movimientos o partidos políticos, participe en la veeduría al proceso de nombramiento de magistrados ante el tribunal constitucional, además de otorgar transparencia al proceso exige la rendición de cuentas y la toma de postura sobre determinados asuntos para que la opinión pública, los partidos políticos, la academia... conozcan a los candidatos y así puedan impulsar o denunciar una determinada candidatura ${ }^{17}$.

En el contexto de una sociedad pluralista, bajo una constitución repleta de principios y valores, y con vocación normativa directa, la configuración del derecho constitucional no debería ser ajena a las discusiones de naturaleza política por el significado de las disposiciones de naturaleza moral. La forma como se consigue la legitimidad democrática de la constitución es construyendo canales deliberativos para incorporar en la interpretación constitucional amplias perspectivas sociales. Ello implica una responsabilidad, tanto de la ciudadanía que se organizan, como de las cortes que establecen mecanismos para realizar dicha articulación.

En Latinoamérica donde la Realpolitik se define por infortunados factores, resultan de singular relevancia análisis en torno a la importancia de consolidar una ciudadanía activa en la definición de su destino como sociedad y al fortalecimiento de una democracia robusta, particularmente desde sus posibilidades de institucionalización. Si bien el cabildeo y la agregación

\footnotetext{
16 “Paradójicamente la posibilidad de que haya desacuerdos sobre el significado de la Constitución preserva su autoridad, ya que permite a personas con convicciones muy diferentes considerar que expresa sus compromisos más fundamentales y que constituye la norma fundacional”.

17 En Colombia hay una experiencia valiosa en este sentido. En 2008 se conformó una coalición de varias organizaciones de la sociedad civil ("Elección visible”) para hacer seguimiento a los procesos de nominación y elección de magistrados de las altas cortes. Véase http://eleccionvisible.com
} 
de preferencias privadas en el proceso político son (no males necesarios sino condiciones) inevitables, un constitucionalismo sensible en su configuración interpretativa y dogmática a los sentires y reclamos de la población civil organizada, a la democracia, resulta esencial para construir sistemas políticos más justos y vinculantes, y si, en últimas, pretendemos constituirnos como ciudadanía en una fuente auto-originante de pretensiones y reclamos, como diría Rawls.

\section{BIBLIOGRAFÍA}

ALEXY, Robert. Revisión judicial de constitucionalidad como representación argumentativa (trad. de Leonardo García J.). En: Juan Carlos Henao (ed.) Diálogos constitucionales con el mundo. Bogotá: Universidad Externado - Corte Constitucional, 2013.

BALKIN, Jack. Respect-Worthy: Frank Michelman and the Legitimate Constitution. En: Tulsa Law Review No. 39, 2004.

; SIEGEL, Reva. The Constitution in 2020. Oxford University Press, 2009.

BARRON, David. What's Wrong with Conservative Constitutionalism? Two Styles of Progressive Constitutional Critique and the Choice They Present. En: 1 Harvard Law \& Policy Review, 2006.

BARROSO, Luís R. El neoconstitucionalismo y la constitucionalización del derecho. El triunfo tardío del derecho constitucional en Brasil. México D.F.: UNAM-IIJ, 2008.

BELLAMY, Richard; CASTIGLIONE, Dario (Ed.). Constitutionalism in Transformation: European and theoretical perspectives. Oxford: Blackwell, 1996.

CARBONELL, Miguel (Ed.). Neoconstitucionalimo(s). Madrid: Trotta, 4. ed., 2009.

(Ed.). Teoría del neoconstitucionalismo. Madrid: Trotta, 2007.

; GARCÍA JARAMILLO, Leonardo (Ed.). El canon neoconstitucional. Bogotá: Universidad Externado, 2010; 2. ed., Madrid: Trotta, 2010.

; VÁZQUEZ, Rodolfo. Estado de derecho. Concepto, fundamentos y democratización en América Latina. México D.F.: Siglo XXI, 2002.

DWORKIN, Ronald. Freedom's Law. Cambridge: Harvard University Press, 1996.

. La lectura moral de la constitución y la premisa mayoritaria. En: GARCÍA JARAMILLO, Leonardo (Ed.). Nuevas perspectivas sobre la relación/tensión entre la democracia y el constitucionalismo. Lima: Grijley, 2014.

ELY, John. Democracy and Distrust. A Theory of Judicial Review. Cambridge: Harvard University Press, 1980. 
FERRAJOLI, Luigi. Pasado y futuro del estado de derecho. En: CARBONELL, Miguel; VÁZQUEZ, Rodolfo (Ed.) Estado de derecho. Concepto, fundamentos y democratización en América Latina. México D.F.: Siglo XXI, 2002.

. Principia Iuris. Teoria della democrazia. Tomo 2. Roma: Laterza, 2007.

FERRERES, Víctor. Justicia constitucional y democracia. Madrid: CEPC, 2. ed., 2007.

GARCÍA JARAMILLO, Leonardo (Ed.). Nuevas perspectivas sobre la relación/tensión entre la democracia y el constitucionalismo. Lima: Grijley, 2014.

GARCÍA VILLEGAS, Mauricio; REVELO, Javier Eduardo. Mayorías sin democracia. Bogotá: Dejusticia, 2009.

GARGARELLA, Roberto (Comp.) Por una justicia dialógica. El poder Judicial como promotor de la deliberación democrática. Buenos Aires: Siglo XXI, 2014.

. La dificultad de defender el control judicial de las leyes. En: Isonomía, No. 6, abril, 1997.

. La justicia frente al gobierno. Barcelona: Ariel, 1996.

. Una disputa imaginaria sobre el control judicial de las leyes. El "constitucionalismo popular” frente a la teoría de Nino. En: CARBONELL, Miguel; GARCÍA JARAMILLO, Leonardo (Ed.). El canon neoconstitucional. Bogotá: Universidad Externado, 2010; 2. ed., Madrid: Trotta, 2010.

HABERMAS, Jürgen. Facticidad y validez. Madrid: Trotta, 1998.

HAMILTON, Alexander; MADISON, James; JAY, John. The Federalist Papers. Clinton Rossiter (Ed.). New York: New American Library, 1961.

HOLMES, Stephen. Passions and Constraint: On the Theory of Liberal Democracy. University of Chicago Press, 1995.

KRAMER, Larry. "The Interest of the Man”: James Madison, Popular Constitutionalism, and the Theory of Deliberative Democracy. En: Valparaiso University Law Review, Vol. 41, No. 2, 2007.

Press, 2004.

The People Themselves: Popular Constitutionalism and Judicial Review. Oxford University

LEVINSON, Sanford. Constitutional Faith. Princeton University Press, 1988.

NOLTE, Detlef; SCHILLING-VACAFLOR, Almut (Ed.). New Constitutionalism in Latin America. Promises and Practices. Londres: Ashgate, 2012.

OBAMA, Barack. The Audacity of Hope. Random House - Crown Publishers, 2006.

PAULSEN, Michael S. The Most Dangerous Branch: Executive Power to Say What the Law Is. En: Georgia Law Review 217. 1994. 
POST, Robert. Democracy and Equality. En: 603 Annals of the American Academy of Political and Social Science 24, 2006; vers. cast. en: GARCÍA JARAMILLO, Leonardo (Ed.). Nuevas perspectivas sobre la relación/tensión entre la democracia y el constitucionalismo. Lima: Grijley, 2014.

. Democratic Constitutionalism and Cultural Heterogeneity. En: Australian Journal of Legal Philosophy 185, 2000; vers. cast. en: GARCÍA JARAMILLO, Leonardo (Ed.). Nuevas perspectivas sobre la relación/tensión entre la democracia y el constitucionalismo. Lima: Grijley, 2014.

. Equality and Autonomy in First Amendment Jurisprudence. En: Michigan Law Review. No. 95, 1997.

; SIEGEL, Reva. Constitucionalismo democrático (ed. acad. y trad., Leonardo García J.). Buenos Aires: Siglo XXI, 2013.

Review, 2006.

Originalism as a Political Practice: The Right’s Living Constitution. En: 75 Fordham Law

Popular Constitutionalism, Departamentalism, and Judicial Supremacy. En: 92 California Law Review 1027, 2004; vers. cast. en: POST, Robert; SIEGEL, Reva. Constitucionalismo democrático (ed. acad. y trad., Leonardo García J.). Buenos Aires: Siglo XXI, 2013.

. Roe Rage: Democratic Constitutionalism and Backlash. En: 42 Harvard Civil Rights-Civil Liberties Law Review 373, 2007; vers. cast. en: POST, Robert; SIEGEL, Reva. Constitucionalismo democrático (ed. acad. y trad., Leonardo García J.). Buenos Aires: Siglo XXI, 2013.

PRIETO SANCHÍS, Luis. El constitucionalismo de los derechos. Madrid: Trotta, 2013.

RAWLS, John. Political Liberalism. New York: Columbia University press, 1993; trad., Liberalismo político. México D.F.: FCE, 1995.

. The Domain of the Political and Overlapping Consensus. En: New York University Law Review. Vol. 64, No. 2, 1989. Se cita a partir de la versión en: Collected Papers. Harvard University Press, 1999.

RAWLS, John. The Idea of Public Reason Revisited, en: The Law of Peoples. Cambridge: Harvard University press, 1999.

RODRÍGUEZ, Juan Carlos; SELIGSON, Mitchell. Cultura política de la democracia en Colombia, 2011. Actitudes democráticas en la sucesión. Bogotá: Universidad de los Andes, et al., 2011.

SARTORI, Giovanni. Neither Presidentialism nor Parliamentarism. En: LINZ, Juan J.; VALENZUELA, Arturo (Ed.). Presidential or Parliamentary Democracy. John Hopkins University Press, 1990.

SIEDER, Rachel; SCHJOLDEN, Line; ANGELL, Alan. La judicialización de la política en América Latina. Bogotá: Universidad Externado, 2008. 
SIEGEL, Reva. Equality Talk: Antisubordination and Anticlassification Values in Constitutional Struggles over Brown. En: 117 Harvard Law Review 1470, 2004; vers. cast. En: POST, Robert; SIEGEL, Reva. Constitucionalismo democrático (ed. acad. y trad., Leonardo García J.). Buenos Aires: Siglo XXI, 2013.

Why Equal Protection No Longer Protects: The Evolving Forms of Status-Enforcing State Action. En: 49 Stanford Law Review 1111, 1997.

STRAUSS, David. The Living Constitution. New York: Oxford University Press, 2010.

SUNSTEIN, Cass. One case at a Time. Cambridge: Harvard University Press, 1999.

TUSHNET, Mark. Taking the Constitution Away from the Courts. Princeton University Press, 1999. . Weak Courts, Strong Rights. Princeton: Princeton University Press, 2008.

\title{
HOW TO CONCEIVE THE CONFLICT BETWEEN CONSTITUTIONALISM AND DEMOCRACY TODAY? A VIEW FROM THE DEMOCRATIC CONSTITUTIONALISM
}

\begin{abstract}
Since the emergence of normative conceptions of democracy and from the change in the constitutional paradigm after WWII, a tension arose for the simultaneous achievement of two goals, namely, collective self-government (democracy) and the guarantee of fundamental rights and principles (constitution). This tension is expressed, for example, when the constitutional courts revoke a widely accepted law, require certain policy to be enforced, or interpret a constitutional provision in a way that favors a certain group on a morally complex topic. How to support constitutional limits to political action, how to properly articulate the institutional role of the courts with respect to the majority principle, what should the role of constitutional courts be with respect to well-organized civil society, how to increase the constitution's democratic legitimacy. These issues, among others, are addressed by democratic constitutionalism and thus provide elements to consider new ways of thinking about how to conceive this tension.
\end{abstract}

KEYWORDS: Constitutionalism. Democracy. Democratic constitutionalism. Discursive constitutionalism. Political legitimacy. 